\section{9,10-ANTHRAQUINONE-2,6-DISULFONIC ACID DISODIUM SALT/ EPOXY GRAPHITE COMPOSITE FOR ANODE IN MICROBIAL FUEL CELL}

\author{
Mimi Hani Abu Bakara,b,c*, Neil F Pascob, Ravi Gooneratnec, Kim \\ Byung Hongb
}

aFuel Cell Institute, Universiti Kebangsaan Malaysia (UKM), Bangi, Selangor, Malaysia bLincoln Agritech Ltd, Lincoln, Christchurch, New Zealand cLincoln University, Lincoln, New Zealand
Article history

Received

30 November 2015

Received in revised form

4 March 2016

Accepted

16 March 2016

*Corresponding author mimihani@ukm.edu.my

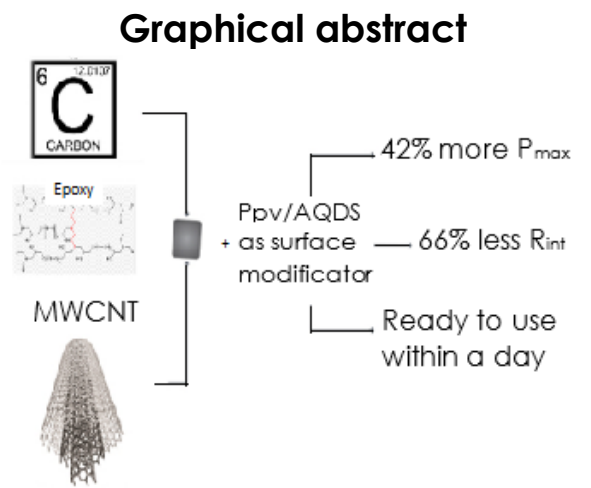

\begin{abstract}
Properties such as electrical conductivity, low resistivity, chemicals and corrosion resistance are mostly found in carbon based materials. Epoxy resin is excellent for electrical insulation and can be used as a conductor with the addition of conductive filler. Combinations of carbon and epoxy show qualities of a conductive electrode, mechanically strong with design flexibility and thus makes them suitable as electrodes in microbial fuel cell (MFC). In this study, graphiteepoxy composites were fabricated with multi-walled carbon nanotube (MWCNT) embedded in the matrix surface. 9,10-Anthraquinone-2,6-disulfonic acid disodium salt/polypyrrole (PPy/AQDS) was used as mediator, covalently electrografted on electrode's surface. Electrochemical stability of anodes during continuous operation were measured in air-cathode MFCs. It appears that maximum power in MFC could be increased up to $42 \%$ with surface modification using PPy/AQDS. Internal resistance $\left(R_{\text {int }}\right)$ could be reduced up to $66 \%$ with the inclusion of MWCNT. These findings show that a one-day fabrication of a-readyto-use conductive electrode is possible for graphite content between $70-80 \%$ $(w / w)$.
\end{abstract}

Keywords: Anode, disodium salt of Anthraquinone disulfonic acid /polypyrrole, graphite-epoxy composite, microbial fuel cell

(C) 2017 Penerbit UTM Press. All rights reserved

\subsection{INTRODUCTION}

In general, an electrode should have qualities such as good electrical conductivity, low resistivity, stable against chemicals and corrosion [1]. These features are mostly found in carbon based materials, such as graphite, thus making it popular material for electrodes [2]. Carbon with biological catalysts in many aspects also conforms to requirements of a biosensor, thus making it acceptable material for electrode fabrication in a microbial fuel cell (MFC). Epoxy resins on the other hand are polymers with good electrical insulation properties [3], which is valuable in the electronics industry. This trait however is adjustable to conductor or semiconductor with the addition of conductive filler [4]. Therefore, a combination of carbon as filler and epoxy resin offers fabrication of a polymer composite, which are conductive [5], effortless in processing as well as moulding, and corrosion resistance $[6,7]$.

Studies conducted on carbon-epoxy composite within the field of fuel cell and biology shows its favourable applications in bipolar plates of proton exchange membrane fuel cell (PEMFC) and biosensor. In the area of bipolar plates, Du and Jana (2007) found that their fabricated carbon-epoxy with 
the total filler loading greater than $50 \mathrm{w} \%$ showed good conductivity, mechanical integrity and chemical stability at temperature above $150^{\circ} \mathrm{C}$ and at $\mathrm{pH}$ 4, much suitable for PEMFC application [5]. Llopis et al. (2005) showed that their amperometric glucose biosensor worked more efficiently when a mixture of glucose oxidase (GOD) powder, epoxy resin, graphite powder and tetrathiafulvalenetetracyanoquinodimethane (TTF·TCNQ) were are applied at a ratio ( $w+\%)$ of 5:76:9.5:9.5 for automated detection of glucose [8]. Kirgoz et al. (2006) discovered that combination of the composite biosensor with a thin layer solution of Pseudomonas putida cells modified the surface could give minimum detection limit on phenol almost 1,000 times lower than thick film microbial biosensor and conventional oxygen electrode [7]. Later, Ocaña et al. (2014) found that aptamer when immobilized on the surface of graphite-epoxy composite gave good detection range for cytochrome $c$ and high sensitivity, which is suitable for an aptasensor [9]. Pumera ef al. (2006) learnt that carbon nanotube-epoxy composite exceeded in both electrochemical and mechanical

Anthraquinone-2,6-disulfonic acid disodium salt/ polypyrrole (AQDS/ PPy) was used here as external mediator. It was electrochemically grafted to the composites' surfaces to induce preferred orientation on the active site and increased the electron transfer rates $[12,13]$. Performance of the graphite-epoxy composites in terms of electrochemical stability as anodes during continuous operation were measured in air-cathode MFCs. For this purpose, characterization of the MFC systems were measured through the polarization and power density analyses.

This study was designed to analyse the graphiteepoxy composite with more than $50 \%$ graphite contents, fabricated in a day using simple technique, on its capability when operated as anode in aircathode MFCs' environment. In addition to that, the effect of embedded MWCNT in composite matrix and its compatibility with AQDS/ PPy electropolymerised on its surface were also assessed through the MFC performance.

\subsection{METHODOLOGY}

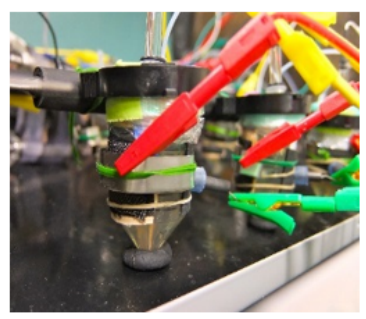

(a)

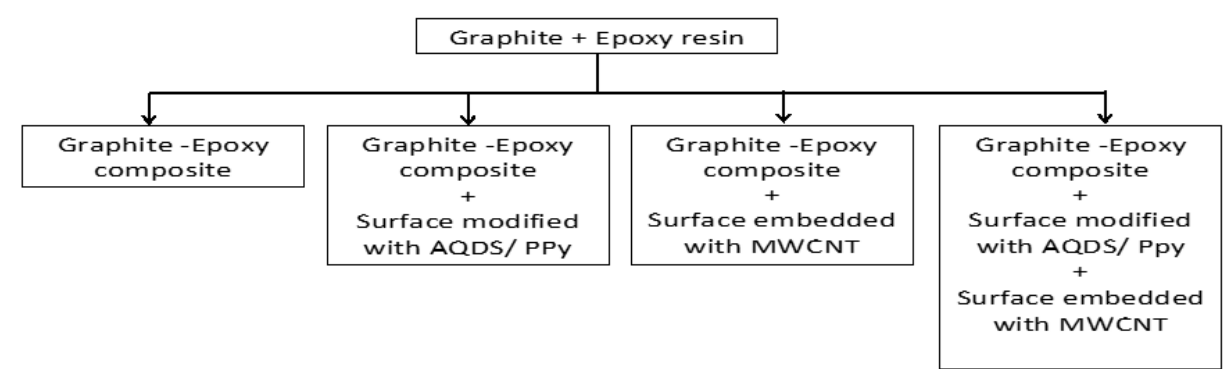

(b)

Figure 1 Cyclone shape MFC (a) and the fabricated graphite-epoxy electrodes (b) used in this study

qualities when compared to graphite-epoxy composite for sensor application [10]. Based on Ma et al. (2010) and Vahedi et al. (2010), carbon nanotubes as filler in the epoxy system had the ability to improve conduction pathway in the epoxy matrix and increased conductivity at loading as low as $0.5 \mathrm{wt}$. \% $[6,11]$. These qualities; strong mechanical properties in bipolar plates and good conductivity as biosensors, gave the indication that the graphite-epoxy composite has the potential to be applied in an MFC application. Unfortunately, it is not known whether there had been studies done more than seven days on the performance of the graphite-epoxy composite as electrodes in MFC. In addition to that, the composite ease of shapes gives more opportunities to flexibility in reactor and electrode designs for MFC performance study.

In this study, graphite-epoxy composites were fabricated with multi-walled carbon nanotube (MWCNT) embedded in the matrix surface. 9,10-

\subsection{Inoculation}

Working buffer was a $50 \mathrm{mM}$ phosphate buffer solution (PBS) containing $\mathrm{NH}_{4} \mathrm{Cl}(0.31 \mathrm{~g} / \mathrm{L}), \mathrm{NaH}_{2} \mathrm{PO}_{4} \cdot 2 \mathrm{H}_{2} \mathrm{O}(3.12$ $\mathrm{g} / \mathrm{L}), \mathrm{Na}_{2} \mathrm{HPO}_{4}(4.58 \mathrm{~g} / \mathrm{L})$, and $\mathrm{KCl}(0.13 \mathrm{~g} / \mathrm{L})$ at $\mathrm{pH} 7$ used for preparing acetate media and for analysis [14, 15]. Basal media of $7 \mathrm{mM}$ acetate containing $\mathrm{CH}_{3} \mathrm{COONa}(1 \mathrm{~g} / \mathrm{L})$, peptone of casein $(1 \mathrm{~g} / \mathrm{L}$ ) and yeast extract $(2 \mathrm{~g} / \mathrm{L}$ ) was dissolved in PBS [16]. The media was autoclaved at $121^{\circ} \mathrm{C}$ for 15 min prior to use. Analytical solution were made using Milli-Q water from EASYpure UV unless otherwise stated. All MFCs were inoculated with effluent from an existing MFC acetate batch fed operated for approximately two years, at $28^{\circ} \mathrm{C}$ with an external resistor of $500 \Omega$.

\subsection{Anode Construction}

The base for the anodes were made from graphite powder mixed with epoxy resin in four different ratios 
by adjusting the weight of the graphite powder $1 \%$ w/w): 53 (total weight of $430 \mathrm{~g}$ ), 73 (total weight of $730 \mathrm{~g}$ ), 78 (total weight of $930 \mathrm{~g}$ ) and 84 (total weight of 1,250 g). The total filler loading was more than 50 wt\% to get desired low inherent resistance of fabricated electrodes. Ratio between the resin (norSKi® part A) and its hardener (norSKi ${ }^{\circledR}$ part $B$ ) followed Pumera et al. (2006) at (w/w) of 20:3 [10]. The combined material was manually blend using spatula until the texture turned flaky and packed into the PCR tubes $(\varnothing 0.4 \mathrm{~cm})$ at the length of $1.5 \mathrm{~cm}$.

For the embedding of MWCNT into the matrix of graphite epoxy composite, only two ratios of graphite powder were used (\% w/w): 73 and 78. This was because graphite powder ratio of $53 \%(\mathrm{w} / \mathrm{w})$ required longer curing hours while graphite powder ratio of $84 \%$ (w/w) could not produce detectable redox peaks when analysed using cyclic voltammetry (CV). MWCNT was prepared through mixing of $1 \mathrm{mg}$ of MWCNT with a $0.4 \mathrm{~mL} \mathrm{~N}, \mathrm{~N}$-Dimethylformamide (DMF) in a vibrator for one min. The mixture was later topped up with $0.6 \mathrm{~mL}$ of $70 \%$ ethanol and sonicated in water bath for five minute. Loading of the MWCNT ink into the base of graphite-epoxy composite was done at different ratios of MWCNT (\% w/w): 0.04 and 0.06 . The MWCNT mixtures were manually blend using spatula and dried under room temperature until the texture became muddy dry. The mixture paste was topped up about $0.3 \mathrm{~cm}$ high on the packed graphite- epoxy resin mixture in the $P C R$ tube, to become the electrode's surface.

Prior to the surface modification methods, each of the packed PCR tubes was centrifuged at 14, $000 \mathrm{~g}$ for 1.5 min to compress and remove remaining air in the paste. A copper wire was inserted at the bottom of each tube for electrical contact. The filled PCR tubes were then cured at $80{ }^{\circ} \mathrm{C}$ for $12 \mathrm{~h}$. They were then allowed to cool at ambient temperature for $30 \mathrm{~min}$. Later, each excess PCR tube wall was cut until the wall was at the same level with the surface of the fabricated graphite-epoxy composite electrodes. The electrode surface area was polished, first on a wet fine emery paper (Norton, P400), then rinsed with Milli-Q water and dried on paper towel before polished on white paper until mirror like surface appeared.

2.3 Electrografting with 9,10-Anthraquinone-2,6Disulfonic Acid Disodium Salt (AQDS)/ Polypyrrole (PPy)

Polypyrrole (PPy) was purified before used [17, 18]. PPy was chosen in this study because of its high electronic conductivity and relatively long period of stability [19] to provide good support for AQDS. PPy was passed to a column of alumina about $4 \mathrm{~cm}$ in height stuffed in a glass pipette. Surface modification of AQDS was done using method described in Feng et al. (2010) [20]. Here, $4 \mathrm{mM}$ PPy was added to $4 \mathrm{mM}$ AQDS in $70 \%$ ethanol and $120 \mathrm{mM}$ hydrochloric acid $(\mathrm{HCl})[19,20]$. The mixture was mixed under nitrogen environment for 5 minutes prior to the electropolymerization. Surface of the electrodes were then modified through electropolymerization in a three-electrode configuration electrochemical cell, free from mixing, yet still under nitrogen environment. An Autolab potentiostat was used to control the constant potential of $+1,100 \mathrm{mV}$ applied to the anode for about $1 \mathrm{~h}$ (tQuiet $=5 \mathrm{~s}, t_{1 \mathrm{st} \text { step }}=1 \mathrm{~s}$ and $t_{2 \text { nd step }}=1 \mathrm{~s}$ ). The freshly prepared AQDS/ PPy- modified electrode was first rinsed with $100 \mathrm{mM} \mathrm{HCl}$ and water before thoroughly rinsed in $100 \mathrm{mM}$ PBS.

\subsection{Single Chamber Air-Cathode Microbial Fuel Cell}

Four cyclones shaped MFCs with anode compartment capacity of $25 \mathrm{~mL}$ were constructed from a $50 \mathrm{~mL}$ Falcon tube (ø $3 \mathrm{~cm}$ ) (Figure 1a). Tube wall of $3.5 \mathrm{~cm} \times 2.4 \mathrm{~cm}$ was cut and glued with cation exchange membrane (Ultrex) from BASF Fuel Cell Inc. (Somerset, NJ, USA) while its opposite wall was cut at $1.4 \mathrm{~cm} \times 1.4 \mathrm{~cm}$ and glued with butynol Dunlop sheet with one small hole punctured for working electrode. The Falcon tube cap was used to cover the cyclone MFC and was equipped with three holes: a small square about $1 \mathrm{~cm} \times 1 \mathrm{~cm}$ for reference electrode (Ag/ AgCl) during the working electrode potential poising and electrochemical analysis, and one small circle of $\varnothing 0.15 \mathrm{~cm}$ for incoming gas. An air-cathode from a 10\% Pt-carbon cloth (Fuel Cell Earth LLC, Stoneham, MA) was fastened to the exterior wall of the Ultrex membrane with a nickel strip and insulated garden wires. The nickel strip acted as current collector at the cathode. The anode compartment was kept anoxic through continuous gassing with oxygen-free nitrogen. The working electrode was the fabricated graphite -epoxy composite electrodes of $\varnothing$ $0.4 \mathrm{~cm}$ (Figure 1b). The graphite -epoxy composite electrodes were placed almost $90^{\circ}$ facing the Ultrex membrane interior wall at a constant distance of about 1-2 mm.

\subsection{Operation}

Inoculation method was adapted and adjusted from the method in Watson and Logan (2011), who studied the effect of AQDS/ PPy on carbon felt in dual chambered MFC [21]. Here, about $50 \%$ of each 12 new MFCs were filled with anolyte and topped up with acetate media. The anolyte came from a two year old acetate fed MFC, where its early culture originated from aerobic trickling filter. The electrodes were then connected with a $1,000 \Omega$ resistor.

\subsection{Analyses}

Cell voltage $(E, m V)$ across the external resistor were measured every six times daily using a four channel Quadstat 164 potentiostat (eDAQ Pty Ltd, NSW, Australia) with continuous recording using an e-corder 1621 (eDAQ Pty Ltd, NSW, Australia) data acquisition system. Current $(I, \mathrm{~mA})$ and power $(P, \mathrm{~mW})$ were calculated using the Ohm's law, I=E/R ext, where Rext is 
the applied external resistance. The current density anode area, $\mathrm{mA} / \mathrm{cm}^{2}$ ) and power density (I $E$ / Anode area, $\mathrm{mW} / \mathrm{m}^{2}$ ) are normalized by the projected area of the anode.

Cyclic voltammetry (CV) was measured using a BASi epsilon C3 cell stand with potentiostat (BASi, Indiana, US). A three-electrode system was used, comprising a coiled platinum wire as auxiliary electrode, an $\mathrm{Ag} / \mathrm{AgCl}$ electrode as reference electrode and the fabricated anodes as working electrode. The scan rate applied was $20 \mathrm{mV} / \mathrm{s}$ between -250 to $+500 \mathrm{mV}$ in $50 \mathrm{mM}$ ferricyanide/ ferrocyanide. The experiment was performed at room temperature in a Faraday's cage.

Polarization curve and the power density curves were produced by using anode potential poising method, adapted from linear sweep voltammetry method of Lanas and Logan (2013) [22]. In this study, anode became the working electrode and cathode as the counter and reference electrode. The polarization curves were obtained starting with open circuit voltage (OCV) with each potential changed in decreasing order after every pseudo steady-state achieved, or not more than $20 \mathrm{~min}$ intervals (whichever comes first) over a complete fed batch cycle. Analysis was conducted once the voltage output was stabilized after replenishing the media.

\subsection{RESULTS AND DISCUSSION}

\subsection{Fabrication of Graphite-Epoxy Composite Anodes}

The inherent resistances measured for the fabricated graphite-epoxy composites in this study were also compared to the $\varnothing 3 \mathrm{~mm}$ commercial graphite rod and a $20 \%$ (w/w) graphite-epoxy composite fabricated by Corb et al. (2007), which was fabricated using a hot press machine at $80^{\circ} \mathrm{C}$ for $40 \mathrm{~min}$ (Table 1) [2].

Table 1 Inherent resistance measured for graphite-epoxy composite anodes

\begin{tabular}{|c|c|c|c|}
\hline \multirow{3}{*}{$\begin{array}{l}\text { Graphite \% } \\
(w / w)\end{array}$} & \multicolumn{3}{|c|}{ Inherent Resistance $(\Omega)$} \\
\hline & \multicolumn{3}{|c|}{$\%$ MWCNT (w/w) } \\
\hline & 0 & 0.04 & 0.06 \\
\hline $20^{*}$ & 7.3 & not available & not available \\
\hline 53 & 34.0 & not available & not available \\
\hline 73 & $6.1 \pm 0.3$ & $5.7 \pm 0.4$ & $5.8 \pm 0.4$ \\
\hline 78 & $4.3 \pm 0.3$ & $4.0 \pm 0.3$ & $4.4 \pm 0.5$ \\
\hline 84 & $4.6 \pm 0.5$ & not available & not available \\
\hline $\begin{array}{l}\text { ø } 3 \mathrm{~mm} \\
\text { commercial } \\
\text { graphite rod }\end{array}$ & $0.4 \pm 0.0$ & not available & not available \\
\hline $\begin{array}{l}\text { *Corb, I., F. Mane } \\
\text { PickenJ. Schoonm } \\
\text { thickness of } 1 \mathrm{mn} \\
\text { electrodes in this }\end{array}$ & $\begin{array}{l}\text { Radovar } \\
\text { evaluat } \\
\text { sample } \\
\text { vere eva } \\
6 \mathrm{~mm}^{2} \text {. }\end{array}$ & $\begin{array}{l}\text {. Pop, G. Bur } \\
\text { the inherent re } \\
\text { ea of } 81 \mathrm{~mm}^{2} \\
\text { ted at sample }\end{array}$ & $\begin{array}{l}\text { P. Malchev, S } \\
\text { ance at sample } \\
\text { the fabricated } \\
\text { kness of } 1.5 \mathrm{~cm}\end{array}$ \\
\hline
\end{tabular}

The commercial graphite rod by far having the least inherent resistance in this study most probably due to the fabrication technique applied by the industry, which also involves heating above $2,000{ }^{\circ} \mathrm{C}$. Samples from $53 \%$ graphite had much higher resistance than the other graphite-epoxy composite samples in this study. At the same time, the curing time applied in this study proved not to be sufficient for $53 \%$ graphite where the surfaces were easily penetrated from the prodding of the multimeter probes. The incomplete curing might have built the high inherent resistance for the $53 \%$ graphite. All the fabricated samples showed significant differences (t-Test, $p>0.05$ ) in inherent resistance from the commercial electrode, however showed comparable inherent resistance with the graphite-epoxy composite electrode consisting of $20 \%$ graphite [2]. Sandler et al. (1999) reported that the critical filler volume fraction for percolation, a conductive path created through three-dimensional network of conductive filler particles, is between 5 and 20 vol. \% [23]. Llopis et al. (2005), Corb et al. (2005) and Ocaña et al. (2014) used a filler as low as $20 \%$ (w/w) to fabricate good graphite-epoxy composite biosensors that exhibited good conductivity $[2,8,9]$. However, to fabricate an epoxy composite with very low filler contents, either a long curing time period is required (more than two days) $[8,9]$ or require the help of expensive machinery, such as hot pressed machine [2].

O'Hare et al. (2002) however, had used filler contents ranging between 40 to $60 \%$ for their electrodes and cured them by degassing in vacuum oven [24]. They discovered that only the electrode with $60 \%$ filler gave voltammetric peaks response similar to the classic peaks shaped of a solid macroelectrode. By increasing the volume filler fraction to more than $60 \%(\mathrm{w} / \mathrm{w})$ in this study, a graphite-epoxy composite was able to be fabricated in less than a day, without using expensive machinery and complex method, while at the same time able to show good conductive behaviour. Introduction of $0.04 \%$ MWCNT into the surface matrix had reduced the inherent resistance of the plain graphite-epoxy composite samples, although not significantly (t-Test, p $>0.05$ ) by $7 \%$ less for both 73 and $78 \%$ samples (Table 1). For samples with $84 \%$ graphite, the addition of $0.04 \%$ MWCNT into the surface matrix had turned the surface very dry and brittle. After increasing the concentration of MWCNT to $0.06 \%$, the inherent resistance of each samples had increased to $2 \%$ for $73 \%$ graphite, $9 \%$ for $78 \%$ graphite and had caused very brittle surface for $84 \%$ graphite. The embedding of $0.04 \%$ MWCNT within composite matrix that consists of graphite more than $70 \%$, was able to bring down the inherent resistance of the graphite-epoxy composite slightly. However, adding another $0.02 \%$ more had proven to give unfavourable effect through increasing the inherent resistance for the samples. Both samples from the 73 and $78 \%$ graphite might end up like the $84 \%$ graphite samples if more than $0.06 \%$ MWCNT added into its system. Though the MWCNT could contribute towards reinforcement of a MWCNT- 
epoxy composite system [25], too much filler in an epoxy system will create non-homogeneity in dispersion, especially when using simple hand shearing as applied in this study. This may have a lesser effect on conductivity [25] but increases the possibility of mechanical failure. It was reported that the structural failure in one of the studies of MWCNT-epoxy composite system, was due to the addition of MWCNT from 0.05 to $0.5 \%(\mathrm{w} / \mathrm{w})$ [6]. They explained that the increased in fillers will prevent the movement of polymer chains from the epoxy causing the system to become brittle. The amount of low loading however, is dependent on epoxy system, aggregation mechanism and the type of filler applied [26]. In this study, the MWCNT was added into an epoxy mixture that already had graphite as its filler. Therefore the reason of too much filler might have led to the surface failure of $84 \%$ graphite samples.
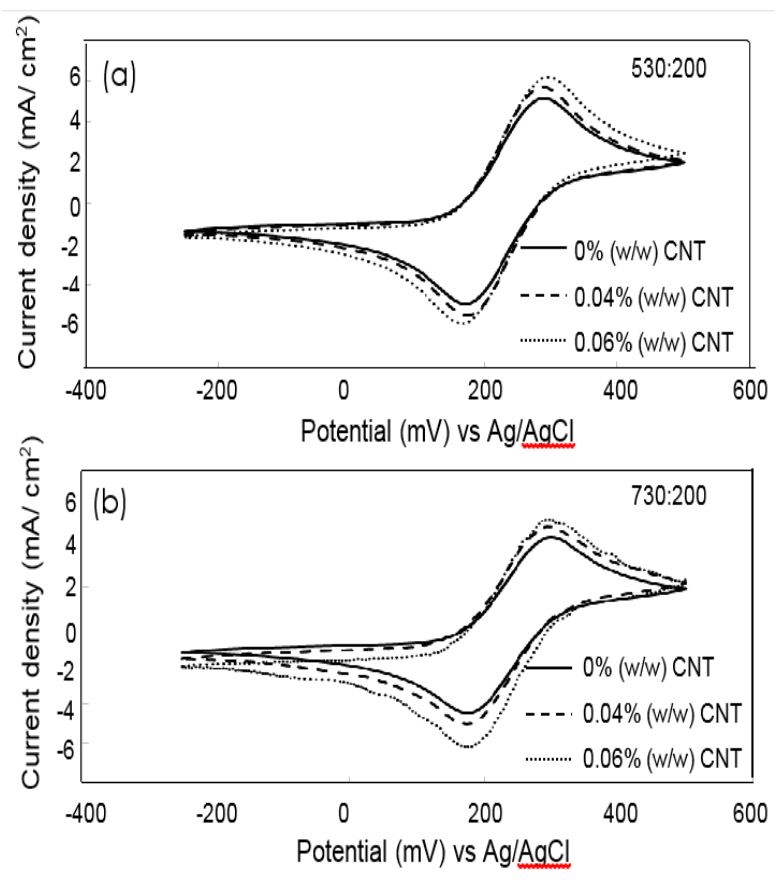

Figure 2 Cyclic voltammograms between different MWCNT loadings in graphite-epoxy composite anodes at scan rate $20 \mathrm{mV} / \mathrm{s}$ and in $50 \mathrm{mM}$ ferricyanide/ferrocyanide electrolyte at room temperature $(n=3)$

$E_{1 / 2}$ for:

$73 \%$ (w/w) graphite (530:200) (a):

No CNT $=231 \pm 0.3$

$78 \%(w / w)$ graphite $(730: 200)$ (b):

No $C N T=239 \pm 2.0$

$0.04 \%(\mathrm{w} / \mathrm{w}) \mathrm{CNT}=236 \pm 0.3 \quad 0.04 \%(\mathrm{w} / \mathrm{w}) \mathrm{CNT}=236 \pm 1.2$

$0.06 \%(w / w) C N T=231 \pm 0.2 \quad 0.06 \%(w / w) C N T=236 \pm 4.6$

The ability of the fabricated epoxy composite electrodes to deliver current response from the reaction of electrolyte can be measured through $\mathrm{CV}$. The redox potential of the ferricyanide/ ferrocyanide calculated from the half waves, $E_{1 / 2}$ obtained from the plain graphite-epoxy composite electrodes shows astray from the standard reduction potential $E^{\circ}$ of ferricyanide/ ferrocyanide. When the ,E' ${ }^{\circ}$ of ferricyanide/ ferrocyanide is $+162 \mathrm{mV}$ (vs Ag/ AgCl) [27], the calculated $E^{\circ}$ ' from the fabricated electrodes were: $73 \%$ graphite detected about $69 \mathrm{mV}$ more while $78 \%$ and $84 \%$ graphite detected more than $72 \mathrm{mV}$ (Figure 2). There was no significant difference (t-Test, $p>0.05)$ for $E_{1 / 2}$ detected between the $78 \%$ graphite samples and $\varnothing 3 \mathrm{~mm}$ commercial graphite $\left(E_{1 / 2}=234\right.$ \pm 0.3 ), which was used for comparison.

This shows the likeness in current response ability between the $78 \%$ graphite samples to the $\varnothing 3 \mathrm{~mm}$ commercial graphite. However, there were significant differences (t-Test, $p<0.05$ ) when the $\mathrm{E}_{1 / 2}$ of the commercial graphite was being compared to both 73 and $84 \%$ graphite samples. No $\mathrm{E}_{1 / 2}$ was detected for electrodes with $53 \%$ graphite, which might be due to the incomplete curing. For $78 \%$ graphite samples, the addition of MWCNT on those two MWCNT loadings did not give significant difference (t-Test, $p>0.05$ ) in $E_{1 / 2}$ when compared to its respective plain samples, between the two MWCNT loadings and the $\varnothing 3 \mathrm{~mm}$ commercial graphite. Meanwhile, for $73 \%$ graphite samples, the addition of $0.06 \%$ (W/W) MWCNT had given significant difference ( $t$-Test, $p<0.05$ ) in $E_{1 / 2}$ when compared to the $0.04 \%$ (w/W) MWCNT loading and the $\varnothing 3 \mathrm{~mm}$ commercial graphite. No $E_{1 / 2}$ analysis was done to $84 \%$ graphite samples due to the surface failure after the incorporation of MWCNT into the surface matrix. From the $E_{1 / 2}$ analysis, the $78 \%$ graphite samples show as if the addition of MWCNT into its system did not improve nor worsen the current response ability, unlike $73 \%$ graphite samples where $0.04 \%$ loading was able to improve its current detection. This could be due to the effect of the filler agglomerating during blending and curing, creating conductive network, which covers the nonconductive epoxy area [26]. Although the inherent resistance results show the $\varnothing 3 \mathrm{~mm}$ commercial graphite had the lowest resistance, the $E_{1 / 2}$ performance of the fabricated graphite-epoxy composites (73 and $78 \%$ graphite contents) had showed to be comparable in current response to the $\varnothing 3 \mathrm{~mm}$ commercial graphite in this study albeit the inherent resistances.

For surface modification with PPy and AQDS, 78\% graphite samples and MWCNT loading of $0.04 \%(\mathrm{~W} / \mathrm{W})$ were applied due to not much difference in current response between the two MWCNT loading as well as the low inherent resistance and consistent $E_{1 / 2}$ showed by $78 \%$ graphite samples.

Figure 3 shows that the electrografting technique had successfully modified the electrode surfaces. For the embedded MWCNT with AQDS through the formation of redox potential, was seen at $E_{1 / 2}$ close to $E^{\circ}$ ' of AQDS, $-395 \mathrm{mV}$ (vs $\mathrm{Ag} / \mathrm{AgCl}$ ) [28]. This is promising for application as mediatored anode in $M F C$, due to the $E^{\circ}$ reported for $\mathrm{NAD}^{+} / \mathrm{NADH}$ is -525 $\mathrm{mV}$ (Vs A/AgCl) [29], which is lower than the surface modified electrodes. The results in this study agrees with Feng et al. (2010a), who had obtained $E_{1 / 2}$ at -451 $\mathrm{mV}$ (vs Ag/AgCl) when using pretreated carbon felts as base for the electrodes [20]. Although the peaks 
were not clear for the plain graphite-epoxy composite samples, there are evident current size and $E_{1 / 2}$ differences between the initial modified electrodes and after $24 \mathrm{~h}$ rinsing in $\mathrm{PB}$ solution, where the current size and $E_{1 / 2}$, became smaller in current and slightly more negative in $E_{l / 2}$ potential. Feng et al. (2010a) also observed the difference in peaks size and clarity between two different materials, glass carbon and carbon felt, after their surface modified with AQDS/ PPy [20]. They explained that curves with larger currents represented enhancement made by PPy/AQDS on the modified surfaces while good peak clarity denotes the low charging inherit current by the electrode. The shift of waves to negative potential in voltammetry analysis reflected the change in the equilibrium of the active redox couple as a function of the equilibrium constant, $\mathrm{Keq}=\left[\mathrm{OH}^{-}\right]\left[\mathrm{H}^{+}\right] /\left[\mathrm{H}_{2} \mathrm{O}\right]$, and can be mathematically explained by the Nernst equation, $E=E^{\circ}-(R T / F)^{*} \ln \left([C] / K_{\text {eq }}[A]\right)[30]$. The $R$ represents the gas constant of $8.3147 \mathrm{~J} / \mathrm{K} \mathrm{mol}, T$ represents the temperature, $F$ represents the Faraday constant of $96,485 \mathrm{C} / \mathrm{mol}$ and [C] represents the reduced concentration of substrate $[A]$ in $\mathrm{mol} / \mathrm{dm}^{3}$ when species $A$ is in equilibrium with species $B$ from $A$ $\leftrightharpoons \mathrm{B}, \mathrm{B}+\mathrm{e} \leftrightharpoons \mathrm{C}$. The rinsing had removed the excess modification from the electrode surface. This might have caused the electrode surface to become less acidic, subsequently reducing the $K_{\text {eq }}$ and eventually pushing the wave towards negative potential.

\subsection{Power Generation}

The main aim of this study was to fabricate strong and easy- to- mould graphite-epoxy composites using simple methods described in the anode construction section. The prepared electrodes were used as anodes in MFC operations and the performance was measured through anodes polarization and power density on the $13^{\text {th }}$ day after start up. The electrodes polarization results (Figure $4 a$ \& b) showed that between the fabricated anodes, open circuit potential (OCP) for anodes from MFC2 and MFC2m, gave lower OCP (more negative), -192 mV (vs. $\mathrm{Ag} / \mathrm{AgCl}$ less by $62 \%$ than MFCl and MFClm. The lower OCP observed from these anodes show the contribution of MWCNT in keeping down the anode potential regardless with or without the AQDS/ PPy for surface modification. Low anode potential, as close to the $\mathrm{E}^{\circ}$ of $\mathrm{NAD}^{+} / \mathrm{NADH}$ is necessary to prevent the bacteria from gaining metabolic energy, thus reducing maximum attainable voltage for MFC [27]. These OCP for anodes however are $56 \%$ more shifted to the positive potential than $E_{1 / / 2}$ of surface modified graphite-epoxy with AQDS/ PPy recorded in CV using 0.1 M PB, free from bacterial cell (Figure 3). This occurrence was also reported by Feng et al. (2010a) where the CV analysis showed that peak waves for their AQDS/ PPy modified carbon felt as anodes in MFC were shifted towards the positive potentials when compared to the surrounding without bacterial cell [20]. Based on Logan (2008), bacteria regulate the concentration ratio of the reduced/ oxidized species

to maximise the degradation of substrate through $\mathrm{NAD}^{+} / \mathrm{NADH}$, and to transfer the electrons to the anode electrode through other terminal enzymes, which has different potentials [29].
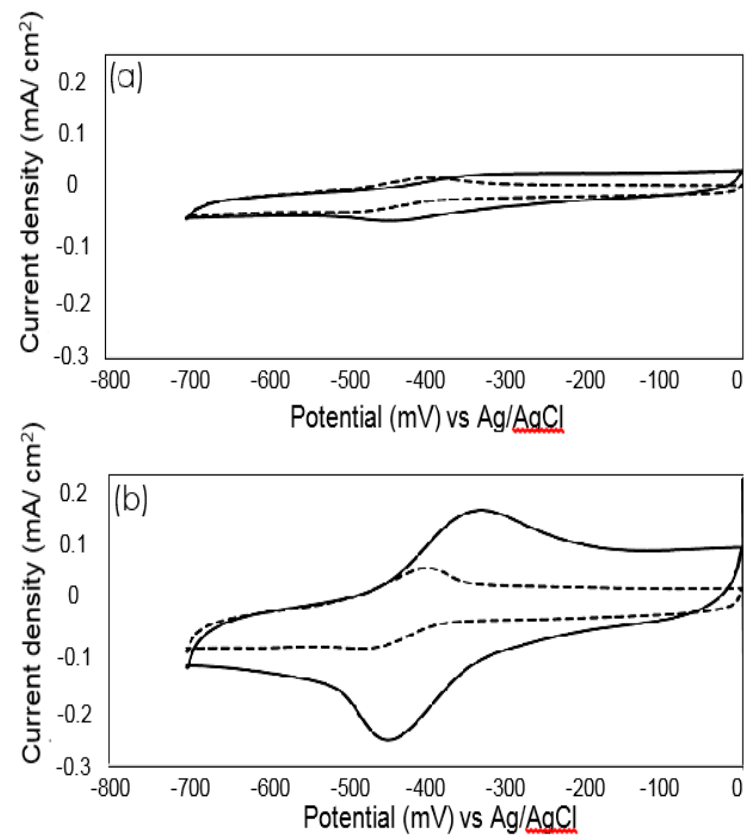

Figure 3 Cyclic voltammograms of AQDS/ PPy surface modified on $78 \%$ graphite samples (a) without and (b) with $0.04 \%(\mathrm{~W} / \mathrm{W})$ MWCNT loading embedded in the surface of composite matrix before $(-)$ and after $24 \mathrm{~h}$ rinsing (- - ) in 0.1 M PB electrolyte at room temperature. Scan rate used was $20 \mathrm{mV} / \mathrm{s}$.

El/2 for:

Without MWCNT (a): $0 \mathrm{~h}$ rinsing $=$ not available After $24 \mathrm{~h}$ rinsing $=$ not available

Therefore, it seems that the anode potential will vary according to the bacterial strain dominating the electrode and whether the electrode is with or without biofilm on it. The existence of MWCNT in the anode matrix however did not show any improvement (decreasing) in the overpotential. It gave a significant increase in anode potential, about $214.5 \mathrm{mV}$ (from 164 to $+50.5 \mathrm{mV}$ ). In fact, this is $38 \%$ higher than MFC 1 to drive similar current densities from 0 to $176 \mathrm{~mA} / \mathrm{m}^{2}$. With the introduction of AQDS/ PPy for surface modification, a low overpotential of $24 \mathrm{mV}$ (from -72 to $-48 \mathrm{mV}$ ) was achieved by MFC $1 \mathrm{~m}$, while the current densities were pushed further from 0 to $330 \mathrm{~mA} / \mathrm{m}^{2}$ (Figure 4a). The surface applied mediator acts as catalyst on the electrode and at the same time reduced the large overpotentials of the electrodes $[20,31]$. For the cathode, the application of commercial Pt on carbon clothes were made consistent for each MFCs in this study, and the overpotential from cathode electrodes due to the 
oxidation reduction reaction were much higher than the anode electrodes [32]. Therefore, the cathode electrodes with large overpotentials became the limiting factor, which indicates the domination on the cell voltage output [33]. It is necessary to get low overpotential since electrode overpotential in an MFC is a constitution of three basic losses, 1) activation due to energy lost during electron transfers, 2) bacterial metabolism through substrate oxidation, and 3) mass transport referring to flux of reactants and products during the reaction [29]. In addition to that, these high overpotentials are shown clearly in the power curves (Figure 4c). The MFClm samples that had low anode electrode overpotentials, gave high maximum power density of $59 \mathrm{~mW} / \mathrm{m}^{2}$ at the current density of $255 \mathrm{~mA} /$ $\mathrm{m}^{2}$; and followed by MFCl with $42 \%$ less, MFC $2 \mathrm{~m}$ with $47 \%$ less and MFC2 with $56 \%$ less in power density than MFClm.

Apart from that, the power density curves also gives quick indication on internal resistance (Rint) of the MFC system, where a power curve leaning more to the right will have lesser $R_{\text {int }}$ than those with symmetrical curves [27]. Rint of an MFC system could refer to resistance experienced by the electrons through the electrodes and interconnections, resistance experienced by the ions through the membranes, the ionic strength in the electrolytes and many more occurred within the MFC system. Using $R_{\text {int }}$ calculation method from Logan (2009), Rint $=P_{\max } / 1^{2}$, where $P$ is maximum power generated and $I$ is current obtained at $P$ maximum [29], MFC $1 m$ and MFC2m samples showed $R_{\text {int }}<100$ $\mathrm{k} \Omega$, while MFC1 and MFC2 had Rint $>100 \mathrm{k} \Omega$.

This shows that the AQDS/ PPy surface modification had successfully bring down the $R_{\text {int }}$ of plain graphite epoxy anodes by $48 \%$ and plain graphite epoxy anodes with embedded MWCNT by $66 \%$. Further comparison of $R_{\text {int }}$ between fabricated anode without surface modification shows that anode embedded with MWCNT had 22\% lesser Rint than the anode samples without MWCNT. This shows the ability of graphite-epoxy composite with embedded MWCNT anodes to bring down the $R_{\text {int }}$ in the MFC system.

The reason for the low maximum power generated by these embedded MWCNT anodes relative to the non-embedded MWCNT, however requires further investigation. The obtained maximum power is much lower in performance than reported, $1,303 \mathrm{~mW} / \mathrm{m}^{2}$ [20], where their surface modification technique of AQDS/ PPy on carbon felt was adopted onto this study's fabricated graphite-epoxy composite samples. Since the only similarity between this study and Feng et al. (2010a) is the surface modification technique [20], the inferior performance observed in my study could be due to the differences in the electrode material used, bacterial culture applied as the inoculum and the catholyte used in in MFC.
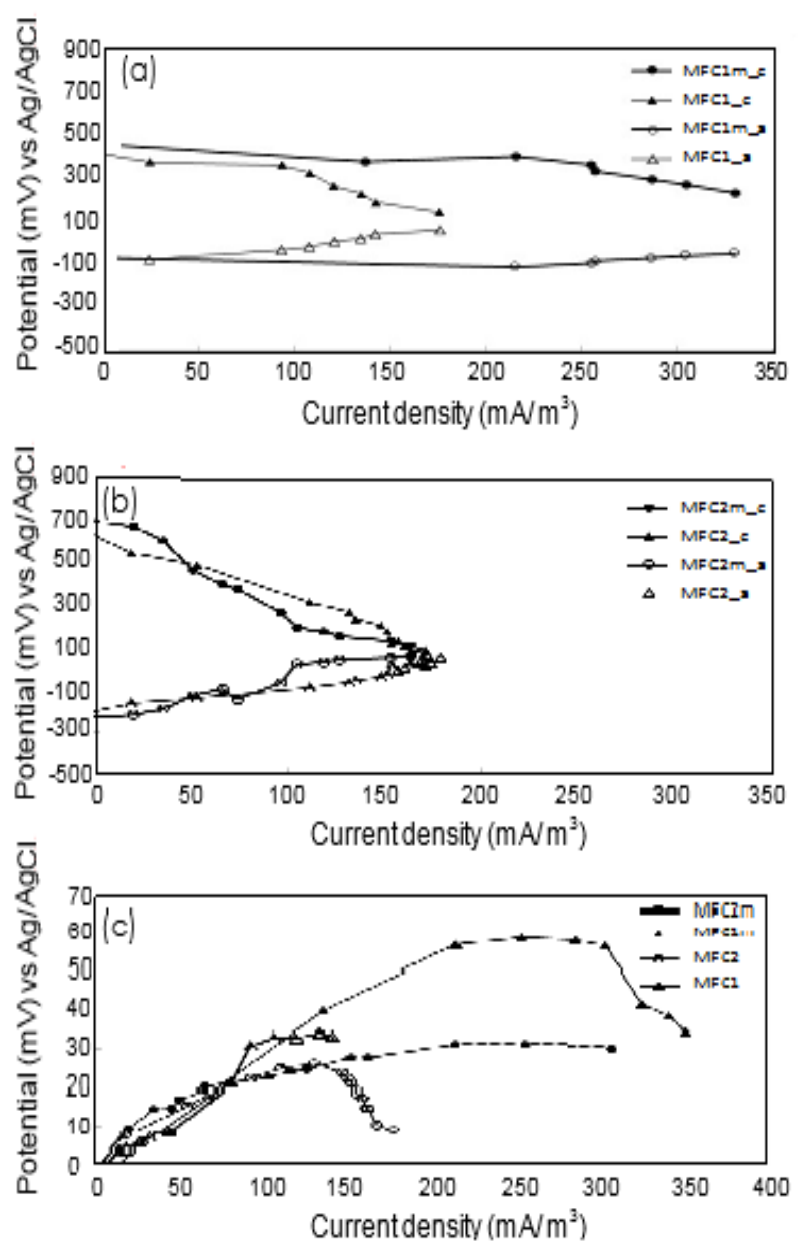

Figure 4 Power generation for MFCs operated with (MFCym, $y=1$, 2) and without (MFCy, $y=1,2$ ) the AQDS/ PPy surface modified anodes on plain graphite-epoxy anodes and on anodes with embedded MWCNT (MFC2x, $x=m, 0$ ) and without the embedded MWCNT (MFClx, $x=$ $m, 0$ ). (a) Anode and cathode polarization curves when using plain graphite as base, (b) when using graphiteepoxy composite embedded with MWCNT as base, and (c) power density curves of four MFCs. Data presented in this figure are representative of at least three independent experiments.

Note:

$c=$ cathode electrode,$a=$ anode electrode and $m=$ AQDS/ PPy surface modification

\subsection{CONCLUSION}

We have demonstrated that it is possible to prepare a ready to use electrode within one day from graphiteepoxy composite with more than $70 \%$ graphite using a simple and cheap technique, while showing similarity in current response close to the conductive commercial graphite rod. We have also shown that the fabricated electrodes are capable to be used as anodes in MFCs, while the $P_{\max }$ could be increased by $42 \%$ and $R_{\text {int }}$ reduced by $48 \%$ through simple surface electrografting with AQDS/ PPy solution. Although 
anode samples with embedded MWCNT were not superior in maximum power density compared to samples without MWCNT, the Rint however showed a reduction by up to $66 \%$ for the anode with PPy/AQDS surface modification. Further studies are required to determine whether the anode with embedded MWCNT will show a higher maximum power density if allowed to operate for a much longer duration.

\section{Acknowledgement}

This work was supported by funding from Ministry of Higher Education of Malaysia (MoHE), University Kebangsaan Malaysia (UKM), Lincoln University, Canterbury, New Zealand and lab facility from Lincoln Agritech Ltd, Christchurch, New Zealand.

\section{References}

[1] Nandy, A., V. Kumar, S. Mondal, K. Dutta, M. Salah, and P. P. Kundu. 2015. Performance Evaluation of Microbial Fuel Cells: Effect of Varying Electrode Configuration and Presence of a Membrane Electrode Assembly. New Biotechnology. 32(2): 272-281.

[2] Corb, I., F. Manea, C. Radovan, A. Pop, G. Burtica, P. Malchev, S. Picken, and J. Schoonman. 2007. CarbonBased Composite Electrodes: Preparation, Characterization and Application in Electroanalysis. Sensors. 7: 2626-2635.

[3] Bhatnagar, M. S. 1996. Epoxy Resins (Overview). The Polymeric Materials Encyclopedia. 2233.

[4] Martin, C. A., J. K. W. Sandler, A. H. Windle, M. K. Schwarz, W. Bauhofer, K. Schulte, and M. S. P. Shaffer. 2005. Electric Field-induced Aligned Multi-wall Carbon Nanotube Networks in Epoxy Composites. Polymer. 46(3): 877-886.

[5] Du, L. and S. C. Jana. 2007. Highly Conductive Epoxy/Graphite Composites for Bipolar Plates in Proton Exchange Membrane Fuel Cells. Journal of Power Sources. 172(2): 734-741.

[6] Vahedi, F., H. R. Shahverdi, M. M. Shokrieh, and M. Esmkhani. 2014. Effects of Carbon Nanotube Content on the Mechanical and Electrical Properties of Epoxy-based Composites. New Carbon Materials. 29(6): 419-425.

[7] Kirgoz, U. A., D. Odaci, S. Timur, A. Merkoci, N. Pazarlioglu, A. Telefoncu, and S. Alegret. 2006. Graphite Epoxy Composite Electrodes Modified with Bacterial Cells. Bioelectrochemistry. 69(1): 128-131.

[8] Llopis, X., A. MerkoلVBi, M. del Valle, and S. Alegret. 2005. Integration of a Glucose Biosensor Based on an EpoxyGraphite-Ttf.Tcnq-God Biocomposite into a Fia System. Sensors and Actuators B: Chemical. 107(2): 742-748.

[9] Ocaña, C., E. Arcay, and M. del Valle. 2014. Label-free Impedimetric Aptasensor Based on Epoxy-graphite Electrode for the Recognition of Cytochrome C. Sensors and Actuators B: Chemical. 191 (0): 860-865.

[10] Pumera, M., A. Merkoci, and S. Alegret. 2006. Carbon Nanotube-Epoxy Composites for Electrochemical Sensing. Sensors and Actuators B: Chemical. 113(2): 617-622.

[11] Ma, P.-C., N. A. Siddiqui, G. Marom, and J.-K. Kim. 2010. Dispersion and Functionalization of Carbon Nanotubes for Polymer-based Nanocomposites: A Review. Composites Part A: Applied Science and Manufacturing. 41 (10): 13451367.

[12] Tasca, F., W. Harreither, R. Ludwig, J. J. Gooding, and L. Gorton. 2011. Cellobiose Dehydrogenase Aryl Diazonium Modified Single Walled Carbon Nanotubes: Enhanced
Direct Electron Transfer through a Positively Charged Surface. Analytical Chemistry. 83(8): 3042-3049.

[13] kumar, G. G., V. G. S. Sarathi, and K. S. Nahm. 2013. Recent Advances and Challenges in the Anode Architecture and Their Modifications for the Applications of Microbial Fuel Cells. Biosensors and Bioelectronics. 43(0): 461-475.

[14] Rader, G. K. and B. E. Logan. 2010. Multi-Electrode Continuous Flow Microbial Electrolysis Cell for Biogas Production from Acetate. International Journal of Hydrogen Energy. 35(17): 8848-8854.

[15] Kim, J. R., B. Min, and B. E. Logan. 2005. Evaluation of Procedures to Acclimate a Microbial Fuel Cell for Electricity Production. Applied Microbial Biotechnology. 68: 23-30.

[16] Atlas, R. M. 2005. Handbook of Microbiological Media. Second Edition ed. Fluorida: Taylor \& Francis Group.

[17] Reiter, S., K. Habermuller, and W. Schuhmann. 2001. A Reagentless Glucose Biosensor Based on Glucose Oxidase Entrapped into Osmium-Complex Modifed Polypyrrole Flms. Sensors and Actuators B. 79: 150-156.

[18] Kumar, A. S. and P. Swetha. 2011. Simple Adsorption of Anthraquinone on Carbon Nanotube Modified Electrode and Its Efficient Electrochemical Behaviors. Colloids and Surfaces A: Physicochemical and Engineering Aspects. 384(1, Äi3): 597-604.

[19] Karami, H. and A. R. Nezhad. 2013. Investigation of PulseElectropolymerization of Conductive Polypyrrole Nanostructures. International Journal of Electrochemical Science. 8: 8905-8921.

[20] Feng, C., L. Ma, F. Li, H. Mai, X. Lang, and S. Fan. 2010. A Polypyrrole/Anthraquinone-2,6-Disulphonic Disodium Salt (Ppy/Aqds)-Modified Anode to Improve Performance of Microbial Fuel Cells Biosensors and Bioelectronics. 25: 15161520.

[21] Watson, V. J. and B. E. Logan. 2011. Analysis of Polarization Methods for Elimination of Power Overshoot in Microbia Fuel Cells. Electrochemistry Communications. 13(1): 54-56.

[22] Lanas, V. and B. E. Logan. 2013. Evaluation of Multi-brush Anode Systems in Microbial Fuel Cells. Bioresource Technology. 148(0): 379-385.

[23] Sandler, J., M. S. P. Shaffer, T. Prasse, W. Bauhofer, K. Schulte, and A. H. Windle. 1999. Development of a Dispersion Process for Carbon Nanotubes in an Epoxy Matrix and the Resulting Electrical Properties. Polymer. 40(21): 5967-5971.

[24] O'Hare, D., J. V. Macpherson, and A. Willows. 2002. On the Microelectrode Behaviour of Graphite, Epoxy Composite Electrodes. Electrochemistry Communications. 4(3): 245250.

[25] Allaoui, A., S. Bai, H. M. Cheng, and J. B. Bai. 2002 Mechanical and Electrical Properties of a Mwnt/Epoxy Composite. Composites Science and Technology. 62(15): 1993-1998.

[26] Martin, C. A., J. K. W. Sandler, M. S. P. Shaffer, M. K. Schwarz, W. Bauhofer, K. Schulte, and A. H. Windle. 2004. Formation of Percolating Networks in Multi-Wall Carbon-NanotubeEpoxy Composites. Composites Science and Technology. 64(15): 2309-2316.

[27] Logan, B. E., B. Hamelers, R. Rozendal, U. Schroder, J. Keller, S. Freguia, P. Aelterman, W. Verstraete, and K. Rabaey 2006. Microbial Fuel Cells: Methodology and Technology. Environmental Science \& Technology. 40(17): 5181-5192.

[28] Du , Z., H. Li , and T. Gu 2007. A State of the Art Review on Microbial Fuel Cells: A Promising Technology for Wastewater Treatment and Bioenergy. Biotechnology Advances. 25: 464-482.

[29] Logan, B. E. 2008. Mechanism of Electron Transfer. New Jersey: John Wiley \& Sons, Inc.

[30] Compton, R., C. B.-. McAuley, and E. Dickinson. 2012. Cyclic Voltammetry: Coupled Homogenous Kinetics and Adsorption. London: Imperial College Press.

[31] Ramakrishnappa, T., M. Pandurangappa, and D. H. Nagaraju. 2011. Anthraquinone Functionalized Carbon Composite Electrode: Application to Ammonia Sensing. Sensors and Actuators B: Chemical. 155(2): 626-631. 
[32] Ghasemi, M., M. Ismail, S. K. Kamarudin, K. Saeedfar, W. R. W. Daud, S. H. A. Hassan, L. Y. Heng, J. Alam, and S.-E. Oh. 2013. Carbon Nanotube as an Alternative Cathode Support and Catalyst for Microbial Fuel Cells. Applied Energy. 102: 1050-1056.
[33] Feng, C., Q. Wan, Z. Lv, X. Yue, Y. Chen, and C. Wei. 2011. One-Step Fabrication of Membraneless Microbial Fuel Cell Cathode by Electropolymerization of Polypyrrole onto Stainless Steel Mesh. Biosensors and Bioelectronics. 26(9): 3953-3957. 